\title{
The Effect of Some Biochemical and Physiological Parameters in Iraqi Patients with Renal Failure
}

\author{
Ahmed Ali Khesbak Jaafar Khalaf Ali \\ Assist Lecturer., Community Health Dept. Karbala Technical Institute, \\ Al- Furat Al-Awsat Technical University,Iraq \\ Mohammad Abdulbaqi Abdulmohsin \\ Lecturer in Community Health Dept. Karbala Technical Institute, \\ Al- Furat Al-Awsat Technical University,Iraq
}

\begin{abstract}
Background: Renal failure occur when the kidneys are unable to bring out the body's metabolic wastes or proceed their regulatory assignment. Objective The study was designed to compere some biochemical and hematological parameters in patents with renal failure and control group. Patients and materials: A case-control study was conducted from September 2018 t0 April 2019 on patients attending the artificial Kidney Unit in Al-Hussein Hospital in holy Karbala Governorate. A total of fifty known cases of renal failure and fifty health persons were selected. Blood samples were taken from both (patients and control) to estimate biochemical and hematological parameters by using specific methods. Results: the results of this study found the high increase $(\mathrm{P}<0.05)$ in concentration of blood urea, serum creatinine, and calcium levels, a significant decreases $(\mathrm{P} \leq 0.05)$ in $(\mathrm{Hb})$ and $(\mathrm{PCV})$ in patients while (ESR) rate were significantly increased $(\mathrm{P} \leq 0.05)$ in these patients when compared to healthy control. Conclusion: In this study conclude that the biochemical parameters are more efficient than hematological parameters in follow-up cases of patients with renal failure.
\end{abstract}

Keywords: Renal failure, parameters, Urea, Creatinine, Calcium.

DOI: $10.7176 / \mathrm{JBAH} / 10-14-04$

Publication date:July $31^{\text {st }} 2020$

\section{Introduction:}

Kidney failure is a disease in which the kidneys may not remove metabolic end-products from the blood and regulate the extracellular fluid's fluid, oxidation and $\mathrm{PH}$ level. Renal failure can occur as an illness that would be acute or chronic. Initially, acute renal failure is sudden and often reversible if it is understood early and properly treated. Chronic renal failure is the final result of unfixable kidney damage. It evolves gradually, usually in the course of years ${ }^{[1]}$.

Chronic renal failure (CRF) is One of the most important public health issues ${ }^{[2]}$. CRF induces a quiet and moderate change in the function of kidney ${ }^{[3]}$. It is usually caused by other disease complications. Unlike (ARF) acute renal failure, which begins rapidly and abruptly, CRF occurs slowly over a period of weeks, months or years $^{[4]}$, if the kidneys perform at less than $10 \%$ of their normal capacity, i.e. glomerular filtration rate (GFR) is less than $15 \mathrm{ml} / \mathrm{min} / 1.73 \mathrm{~m} 2$ and chronic renal failure occurs at the end-stage renal disease (ESRD) ${ }^{[5]}$.

Renal failure events vary widely around the world, and variations are largely dependent on health care systems. 95\% of Popular patients in Australia, quite low in Japan (only 5\% of prevalent patients) and Abnormally high in New Zealand (60\%). In certain countries The majority of patients amplitude from $15 \%$ to $27 \%{ }^{[6]}$. Prevalence levels of more than 30 million people in 7 European countries and North America ${ }^{[7]}$.

Many different symptoms can occur during kidney failure, though sometimes none are present. Somatic symptoms include (reduced urine, swelling of legs, ankles and feet from fluid retention caused by kidney failure to remove water waste, unexplained shortness of breath, elimination of water waste, unseen shortness of breath, excessive drowsiness or fatigue, persistent nausea, confusion, chest pain or pressure, seizures and coma ${ }^{[8]}$.

Kidney failure risk factors may include: cardiovascular disease is often considered the primary factor contributing to renal failure progression the individual's age also plays a vital role with advancing age in the development of renal failure. Cardiovascular disorders, low blood pressure and other important risk factors (diabetes, other kidney disorders, acute malnutrition, blood loss due to injury and serious lung disorders ${ }^{[9]}$.

The aim of this article : study Some biochemical and hematological findings are to be conducted in serum considering urea, creatinine, calcium, pcv, $\mathrm{Hb}$ and ESR rate with renal failure patents and compared with a control group .

\section{2- Materials and Methods:}

\section{2-1-Subjects and Samples}

A case-control study was conducted from September 2018 t0 April 2019 on patients attending the artificial Kidney Unit in Al-Hussein Hospital in holy Karbala province. The cases are reported as renal failure for both sex based 
on the history, clinical examination and taking renal function tests. The study consist of 50 patients (25 males, 25 females) and 50 obviously healthy individuals (23 males, 27 females) from (20 - 70) years old of age. All patients included in this study were non diabetic, non-alcoholism, without viral hepatitis. (5 ml) Venous blood was drawn from each patient Serum was then separated for (10) minutes by centrifugation . Biochemical tests such as blood urea, Serum creatinine were measured by semi-auto analyzerBA-88A (Korea). The electrolyte such as Calcium was estimated by using Genex Elyte 4 device according to manufactured company that approved with it. The criteria of hematology, hemoglobin $(\mathrm{Hb})$ concentration, packed cell volume (PCV) were measured by using automated hematological cell counting (USA) and (ESR) was Evaluated by western green method .

\section{2-2-Statistical analysis}

All statistical procedures of the present article have been carried out by using Excel programs and statistically available software; Statistical Package for the Social Sciences (SPSS) Version 18 by using the Pearson correlation method. All values as mean \pm standard deviation (SD) are expressed. Differences were considered to be significant when the probability $(\mathrm{P})$ was less than $\mathrm{P} \leq 0.05$.

\section{3- Result}

Table1: frequency of gender and age among patients and control

\begin{tabular}{|c|c|c|}
\hline \multicolumn{3}{|c|}{ Control } \\
\hline Percentage $\%$ & Frequency No & Gender \\
\hline $46 \%$ & 23 & Male \\
\hline $54 \%$ & 27 & Female \\
\hline \multicolumn{3}{|c|}{ Patients } \\
\hline Percentage $\%$ & Frequency No & Gender \\
\hline $50 \%$ & 25 & Male \\
\hline $50 \%$ & 25 & Female \\
\hline \multicolumn{3}{|c|}{ Control } \\
\hline Percentage $\%$ & Frequency No & Age \\
\hline $30 \%$ & 15 & $20-35$ \\
\hline $22 \%$ & 11 & $36-45$ \\
\hline $48 \%$ & 24 & $<45$ \\
\hline \multicolumn{3}{|c|}{ Patients } \\
\hline Percentage $\%$ & Frequency No & Age \\
\hline $18 \%$ & 9 & $20-35$ \\
\hline $20 \%$ & 10 & $<45$ \\
\hline $62 \%$ & 31 &
\end{tabular}

The results showed that the patients were enrolled and control were distributed according to gender and age group as shown in table(1) patients were divided into two groups, the male group forming ( $50 \%$ ) of them was found to be equal to female group ( 50\%) while the two groups of control forming (46\%) for male and (54\%) for female. In the same table The distribution of age in renal failure was high in the age $(<45)$ years represented by $31(62 \%)$ patients and $24(48 \%)$ for control.

Table 2: the biochemical parameters in blood serum of patients and control

\begin{tabular}{|c|c|c|}
\hline Parameters & $\begin{array}{c}\text { patients } \\
(\text { mean } \pm \text { SD) }\end{array}$ & $\begin{array}{c}\text { Controls } \\
(\text { mean } \pm \text { SD) }\end{array}$ \\
\hline Urea $(\mathrm{mmol} / \mathrm{L})($ & $23.57 \pm 20.10^{*}$ & $5.52 \pm 1.29$ \\
\hline Creatinine $(\mu \mathrm{mol} / \mathrm{L})($ & $547.06 \pm 200.08^{*}$ & $79.62 \pm 18.30$ \\
\hline Calcium $(\mathrm{mmol} / \mathrm{L})($ & $2.96 \pm 4.55^{*}$ & $2.28 \pm 0.14$ \\
\hline
\end{tabular}

$* \mathrm{P}<0.05$ Significant

Table (2) show a significant change in serum of the diagnostic parameters of kidney functions :blood urea $(\mathrm{BU})$, creatinine $(\mathrm{Cr})$ and calcium $(\mathrm{Ca})$ in comparison to healthy control. There is a substantial increase $(\mathrm{P}<0.05)$ in concentration of blood urea, serum creatinine, and calcium when compared to healthy control .

Table 3: the hematological parameters in blood serum of patients and control

\begin{tabular}{|c|c|c|}
\hline Parameters & $\begin{array}{c}\text { patients } \\
(\text { mean } \pm \text { SD) }\end{array}$ & $\begin{array}{c}\text { Controls } \\
(\text { mean } \pm \text { SD) }\end{array}$ \\
\hline $\mathrm{Hb}(\mathrm{gm} / \mathrm{dl})$ & $9.14 \pm 2.45^{*}$ & $12.76 \pm 2.86$ \\
\hline $\mathrm{PVC} \%$ & $25.35 \pm 1.50^{*}$ & $40.29 \pm 2.00$ \\
\hline $\mathrm{ESR}(\mathrm{mm} / \mathrm{hr})$ & $65.09 \pm 2.09^{*}$ & $9.05 \pm 1.34$ \\
\hline$* \mathrm{P}<0.05 \mathrm{Significant}$
\end{tabular}


Table (3) showed a hematological parameters in blood serum such as hemoglobin ( $\mathrm{Hb})$, packed cell volume $(\mathrm{PCV})$ and erythrocyte sedimentation rate (ESR) and the were a significant decreases $(\mathrm{P} \leq 0.05)$ in $(\mathrm{Hb})$ and $(\mathrm{PCV})$ in patients when compared to healthy control while (ESR) rate were significantly increased $(\mathrm{P} \leq 0.05)$ in these patients when compared to healthy control .

\section{4- DISCUSSION:}

The study result showed a high incidence of biochemical analysis and hematological tests for renal failure patents versus healthy individuals. The present study included 50 patents suffering from renal failure ( 25 male, 25 female) as compared with 50 person healthy individuals ( 23 male, 27 female) as control group and their ages were similar and ranged from $(20-<45)$ as shown in table (1). Kidney failure occurs when the kidneys can not eliminate or perform their regulatory role of body metabolic waste. Substances that are normally disposed of in urine develop in the body fluids due to affected renal excretion and lead to disturbance in the endocrine, metabolic and fluid, electrolyte, and acid-base functions of the body. Renal failure is a systemic illness and is the most prevalent mechanism for many different diseases of the renal and urinary tract. Each year an estimated 42,000 Americans die of irreversible kidney failure ${ }^{[10,11]}$.

In current study there was high significant increase in blood urea, serum creatinine and calcium levels in renal failure patients ( $\mathrm{p} 0.00$ ) as shown in table (2) serum urea increase was mainly caused by the development of the disease, but is heavily influenced either by a catabolic condition or by excessive protein intake, which leads to increased production of protein catabolism waste ${ }^{[12]}$. meanwhile, an increase in creatinine levels is due to a reduced number of working nephrons in patients with renal failure in the serum which would decrease the GFR, which is responsible for a significant decrease in water and solutes ${ }^{[13]}$. In kidney failure patents, excess calcium concentration due to intestinal calcium absorption appears to be reduced. Calcium fractional absorption is inversely related to blood urea concentration. Chronic renal failure patients appear to consume less calcium than normal individuals in their diets his result is consistent with ${ }^{[14]}$.

In other hand there was a significant decrease ( $\mathrm{p}$ 0.02) in hematological parameters such as hemoglobin, PVC as shown in table (3) This result was compatible with ${ }^{[15]}$ because of the (EPO ) erythropoietin hormone induces the action of bone marrow to produce (RBCs) when the kidneys are affected as in patents for renal failure, they do not generate sufficient EPO. As a result, little is achieved by the bone marrow to make (RBCs), which causes anaemia. Certain causes of anaemia in patients with renal failure due to low levels of the following minerals and vitamins contained in meals: vitamin B12, iron, folic acid required for (RBCs) to make haemoglobin, the primary oxygen-carrying protein in haemoglobin $(\mathrm{RBC})$. while the level of ESR in patents increase significantly(p 0.01 ) in compared with healthy individual elevation of the erythrocyte sedimentation rate (ESR) is mostly due to inflammation and infection as a results of the vascular disease and catabolic processes occurring in renal failure as a cause or complements, which are most probably due to elevated circulating levels of inflammatory cytokines such as interleukin-6 ${ }^{[16]}$

\section{Conclusion}

Notes from the above results showed that biochemical parameters levels significantly increased in patients with renal failure otherwise hematological parameters in patients significantly decreased such as $(\mathrm{Hb})$ and (PVC) unlike (ESR) found significantly increased, though the biochemical parameters are more efficient than hematological parameters in follow-up cases of patients with renal failure.

\section{Acknowledgement}

We are very much grateful to wholly our patients involved in current study for their cooperation in aiding us complete our work well. We demand them a long and glad lifetime.

\section{References}

1. Kellum JA, et al. (2011). Acute kidney injury, search date December. BMJ Clinical Evidence. Available online: http://www.clinicalevidence.com.

2- Levey A S, Atkins R, Coresh J, Cohen E P, Collins A J and Eckardt K U.(2007). Chronic kidney disease as a global public health problem: Approaches and initiatives -a position statement from Kidney Disease Improving Global Outcomes. Kidney International; 72: 247-259.

3- Levey A S, Eckardt U, and Tsukamoto Y. (2005). Definition and classification of chronic kidney disease: a position statement from Kidney Disease. Kidney International; 67: 2089-2100.

4- Cox, A. J., Hsu, F.C., Carr, J. J., Freed man, B. I., Bowden, D. W.(2013). Glomerular Filtration Rate and Albuminuria Predict Mortality Independently from Coronary Artery Calcified Plaque in the Diabetes Heart Study. Cardiovasc Diabetol., 12: 68.

5- Degrassi, F., Quaia, E., Martingano, P., Cavallaro, M. and Cova, M.A.(2015). Imaging of Haemodialysis Renal and Extrarenal Findings. Insights Imaging, 6(3): 309 - 321. 
6- Ricci, Zaccaria; Ronco, Claudio (2012). "New in sights in acute kidney failure in the criticallyill". Swiss Medical Weekly 142: w 13662.doi: 10.4414/smw.2012.13662.PMID 2292314.

7- National Kidney and Urologic Disease Information Clearinghouse (2012). "The Kidney and How They Work". National Institute of Diabetes and Digestive and Kidney Disease. Retrieved 1 January.

8- Rose K and Matthew S. (2017). "What are the symptoms of kidney failure, Kidney Failure ".Health line.

9- Malekmakan L1, Haghpanah S, pakfetrat M, Malekmakan A, Khajehdehi P.(2009). Cause of chronic renal failure among Iranian hemodialysis patients. Saudi J. Kidney Dis Transpl. May;20(3):501-4.

10- 1.Brunner, L.S. and Suddarth, D.S., 1988. Textbook of Medical-Surgical Nursing, 6thed., J.B. Lippincott Company, U.S.A., p1033-1038.

11 - 2.Smith,A. F.; Beckett, G. J.; Walker, S. W., and P.W.H., 1998. Clinical Biochemistry,6th ed ., U.S.A.,p5167.

12- Montini,G.,Pisanello,L.,Dacco,V.,Testa,S.,Strologo,L.D.,Taioli,E.,Avolio,L.etal.(2003).Urea percentiles in children with chronic renal failure .Pediatric Nephrol,18:261-265.

13- Guyton,A.C.,Hall,J.E(1996).Micturition, Diuretics and Kidney Disease.In: Textbook of medical physiology. $9^{\text {th }}$ ed.Philadelphia, W.B Saunders company,pp:405

14- Al-Rubae'I,S.HN,Al-khayat,T.H,Muftin,N.Q(2010).Free fatty acids and biochemical changes in Iraqi patients with chronic renal failure .Baghdad science journal .7(1).

15- Kidney Disease. (2012). Improving Global Outcomes (KDIGO) Anemia Work Group. KDIGO clinical practice guideline for anemia in chronic kidney disease. Kidney International Supplements. 2(4):279-335.

16-Ganz, T. Hepcidin, (2003). A key regulator of iron metabolism and mediator for anemia of inflammation. Blood. 102:783-788. 